\title{
GEOMETRIC NONLINEAR BEHAVIOR OF SHALLOW SHELLS BY BOUNDARY CONDITIONS
}

\author{
Prof Kanggeun Park ${ }^{1}$, PhD Dongwoo Lee ${ }^{2}$, Architect Dongil Choe ${ }^{3}$, Prof Mijin Park ${ }^{4}$
}

\begin{abstract}
This paper investigates the mechanical characteristics of geometrical nonlinear behavior of shallow shells for boundary conditions of support. The shallow shells with a low rise-span ratio have a snap back and through behavior for a load condition or a support condition. The analytical models are a spherical shell, a cylindrical shell and a quadratic shell. The shells with all its edges hinged or fixed support condition are subjected to a concentrated load at the crown. The load is applied gradually by incrementing the deflection by displacement control. The objective of the study is to compare the load deflection curves according to support conditions or thicknesses. The element in the nonlinear analysis used 3-D four/eight nodes shell element and 3-D laminated composite shell element. In geometric nonlinear behavior of shallow shells, it will be observed for snap back and through behavior for a hinged and fixed support condition. The snap through phenomenon cannot be found in the load deflection curve of shells with the fixed support and the good results are observed for large deflection analysis of shells with hinged supports. .
\end{abstract}

Keywords - Geometrical Nonlinear Behavior, Shallow Shells, Displacement Control, Snap Back and Through Curve

\section{INTRODUCTION}

The shallow structures have a behavior of S-shaped load displacement curve for the special cases by boundary condition, span-rise ratio, thickness or elastic modulus. The load displacement curve is called for the snap back and through phenomenon by gradually increasing displacement and load. The phenomenon is important to estimate the structural stability and the capacity of applied load. Geometric nonlinear analysis with Lagrangian formulation and full Newton-Raphson iteration method is used.

The literature survey of important studies for this study is as follows. Surana [1] investigated the geometrically nonlinear formulation for the curved shell elements, and the good analysis result was observed for large deflection analysis of a hinged spherical shell. Szilard [2] observed the large displacement analysis of a shallow arch structure for comparing the load displacement curve of analysis result and experimental result. Kim et al [3] was investigated for the close agreement between the results for the 4-noded and 8-noded element for large deflection analysis of a two-layer laminated composite cylindrical shell. Park et al [4-6] have been studied for the mechanical characteristics of geometrical nonlinear behavior for large span structures such as cable roof systems or bio-mimics structures by nature inspired design.

The objective of this research is carried out investigating and comparing the geometrical nonlinear behavior of the load deflection curves of shallow shells according to support conditions, thicknesses or elastic modulus. The element in geometrical nonlinear analysis used 3-D four/eight nodes shell element and 3-D laminated composite shell element in element library of NISA 2016 software. In the load displacement curve of geometric nonlinear

${ }^{1}$ Department of Architectural Engineering, I'ST Institute of Technology, Seoul, South Korea

${ }^{2}$ Department of Architectural Engineering, I'ST Institute of Technology, Seoul, South Korea

${ }^{3}$ Department of Architectural Engineering, Incheon Development \& Transformation Corporation, Incheon, South Korea

${ }^{4}$ Department of Architectural Engineering, Incheon National University, Incheon, South Korea 
analysis of shallow shells the snap back and through phenomenon for support conditions at edges will be investigated.

\section{SHELL ELEMNETS FOR A NONLINEAR ANALYSIS OF SHELLS}

\section{A. 3-D general shell element}

In NISA 2016 software the 3-D general shell element includes membrane, bending and transverse shear deformation effects, and is suited for modeling of thick and thin shell structures. The shell element has six degrees of freedom per nodes, but it has no rotational stiffness about the normal to shell surface. The element can be shaped as 4 to 12 nodes quadrilateral, or 3 or 6 nodes triangle.



Figure 1. Face numbering for top and bottom surface and warped quadrilateral

\section{B. 3-D thin shell element}

The 3-D thin shell element includes membrane and bending deformations, and is suited for modeling thin shells. The element is formulated by applying the Kirchhoff assumption of zero transverse shear strain, thus transverse shear effects are not included in the deformation. The element has 6 degree of freedom per node. The element can be shaped as 4 nodes quadrilateral or 3 nodes triangle.

\section{3-D laminated composite shell element}

The 3-D laminate composite shell element includes deformation due to membrane, bending membrane-bending coupling and transverse shear effects, and is suited for modeling thick and thin laminated composite shells. The element consists of a number of layers of perfectly bonded orthotropic materials. The element has six degrees of freedom per node, but it possesses no rotational stiffness about the normal to the shell surface.
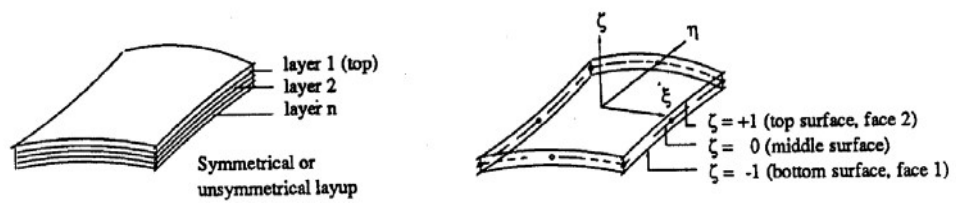

Figure 2. Layer setup and face numbering for top and bottom surface

\section{GEOMETRICAL NONLINEAR BEHAVIOR OF A SPHERICAL SHELL}

A. A spherical shell with hinged support -

This objective of geometric nonlinear analysis is to plot the load displacement curve of a spherical shell with all hinged support at edge. The condition of load is subjected to concentrated load at the center of a crown. The radius of a spherical shell is $2540 \mathrm{~mm}$. The width is $1570 \mathrm{~mm}$. The elastic modulus is applied to two cases for $100 \mathrm{MPa}$ and $1000 \mathrm{MPa}$. The shell in Figure 3 is modeled $10 \times 10$ elements by $3-\mathrm{D}$ general shell element. The hinged boundary conditions are applied on nodes of edges. Figure 4 shows a deformation of a shell with $80 \mathrm{~mm}$ thickness for a concentrated load. In Figure 5 the analysis results of a shell with hinged supports are compared with load displacement curves for the thickness 80, 100 and $120 \mathrm{~mm}$ and elastic modus $100 \mathrm{MPa}$. In Figure 6 the results of a shell with hinged supports are compared with load displacement curves for the thickness 12,14 and $16 \mathrm{~mm}$ and elastic modus $1000 \mathrm{MPa}$. The element for the modeling of nonlinear analysis is the 3-D four nodes shell element. The geometrical nonlinear analysis is performed to Modified Newton-Rapson method. Number of displacement increments is 30 equal increments. Maximum number of iteration allowed per increment is 100 . The tolerance is applied to 0.0001 . The snap through behavior in Figure 5 is shown in $150 \mathrm{~mm}$ displacements, and the curve raise up again $260 \mathrm{~mm}$ displacements more. In Figure 6 the snap through curve is started at $200 \mathrm{~mm}$ displacements, and is 
raised up $260 \mathrm{~mm}$ displacements more.

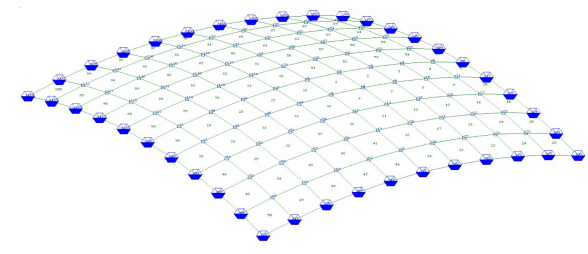

Figure 3. Analytical modeling (thickness $=80,100,120 \mathrm{~mm}$ )

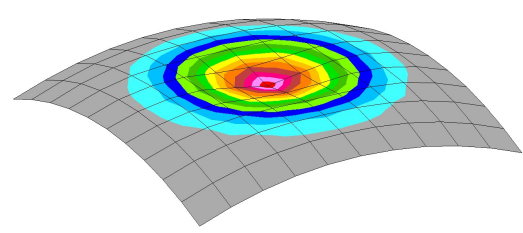

Figure 4. Deformation for a concentrated load (thickness $=80 \mathrm{~mm}$ )

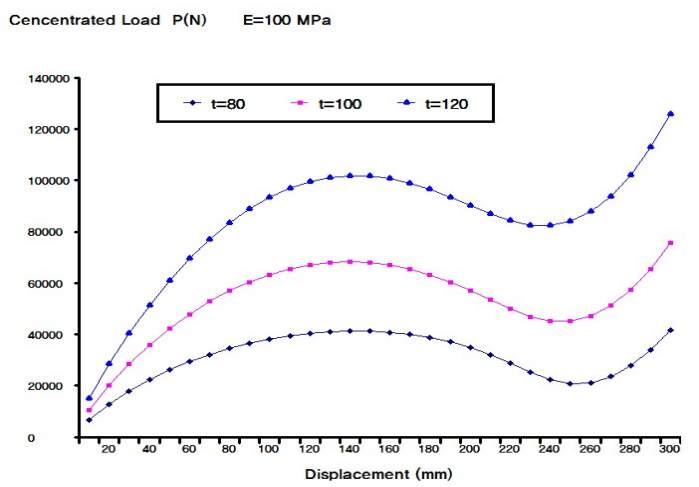

Figure 5. Load displacement curves of a spherical shell with hinged support (elastic modulus $=100 \mathrm{MPa}$, thickness=80, 100, $120 \mathrm{~mm}$ )

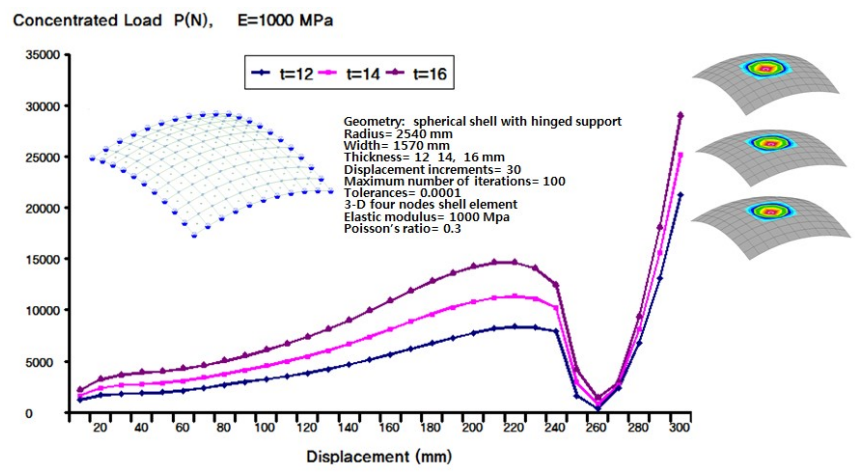

Figure 6. Load displacement curves of a spherical shell with hinged support (elastic modulus $=1000 \mathrm{MPa}$, thickness=12, 14, $16 \mathrm{~mm}$ )

B. A spherical shell with fixed support -

This analysis is to compare the load displacement curve of a spherical shell with fixed supports subjected to concentrated load. The radius of a spherical shell is $2540 \mathrm{~mm}$. The width is $1570 \mathrm{~mm}$. The elastic modulus is two cases for $100 \mathrm{MPa}$ and $1000 \mathrm{MPa}$. The fixed boundary conditions are applied on nodes of edges. Figure 7 shows analytical model and geometry of meshes. Figure 8 shows a deformation contour of a shell with thickness $80 \mathrm{~mm}$ for displacement range 0-300 mm. In Figure 9 the results of a shell with fixed supports are compared with load displacement curves for the thickness 80,100 and $120 \mathrm{~mm}$ and elastic modus $100 \mathrm{MPa}$. In Figure 8 the results of a shell with fixed supports are compared with load displacement curves for the thickness 12, 14 and $16 \mathrm{~mm}$ and elastic modus $1000 \mathrm{MPa}$. The snap through phenomenon of load deflection curve is not observed in Figure 9 and 10. 


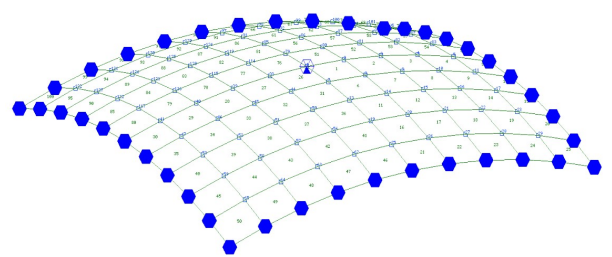

Figure 7. Analytical modeling (thickness $=80,100,120 \mathrm{~mm}$ )

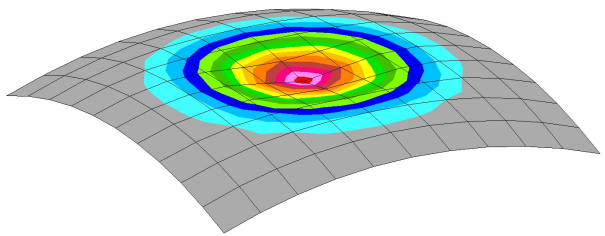

Figure 8. Deformation for a concentrated load (thickness $=80 \mathrm{~mm}$ )

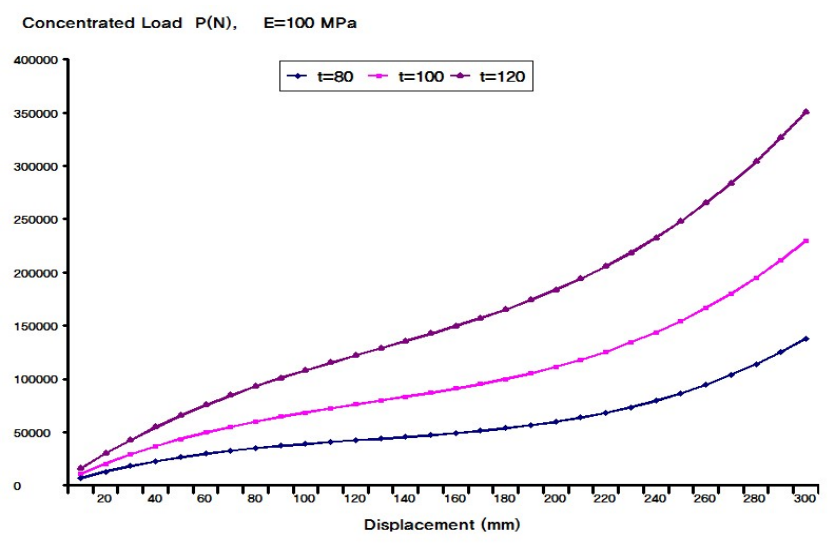

Figure 9. Load displacement curves of a spherical shell with fixed support (elastic modulus $=100 \mathrm{MPa}$, thickness=80, 100, 120 mm)

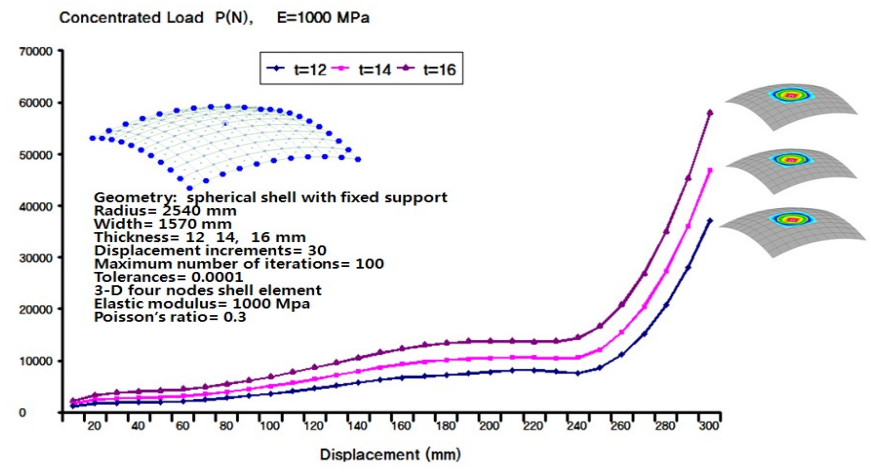

Figure 10. Load displacement curves of a spherical shell with fixed support (elastic modulus $=1000 \mathrm{MPa}$, thickness=12, 14, $16 \mathrm{~mm}$ )

\section{GEOMETRICAL NONLINEAR BEHAVIOR OF A CYLINDRICAL SHELL}

A. A cylindrical shell with hinged support -

This objective is to investigate the load displacement curve of a cylindrical shell with hinged support subjected to concentrated load. The radius of a cylindrical shell is $2540 \mathrm{~mm}$. The width is $508 \mathrm{~mm}$. The elastic modulus is 1000 MPa. The cylindrical roof shell in Figure 11 is modeled using 36 elements. The hinged boundary conditions are applied on nodes of two edges. Figure 12 show a deformation of a cylindrical roof with thickness $12 \mathrm{~mm}$ for a concentrated load and contour range of deflection 0-30 $\mathrm{mm}$. In Figure 13 the results of a shell with hinged supports are compared with load displacement curves for the thickness 12, 14 and $16 \mathrm{~mm}$ and elastic modus $1000 \mathrm{MPa}$. In Figure 14 the results of a shell with all hinged supports are compared with load displacement curves for the thickness 12, 14 and $16 \mathrm{~mm}$ and elastic modus $1000 \mathrm{MPa}$. The element used the 3-D eight nodes shell element. Number of displacement increments is 30 equal increments. Maximum number of iteration allowed per increment is 100. The applied tolerance is 0.0001 . Figure 13 shows snap through curves that are started $12 \mathrm{~mm}$ displacements. 


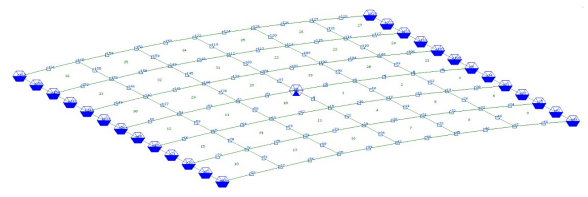

Figure 11. Analytical modeling (thickness=12, 14, 16mm)

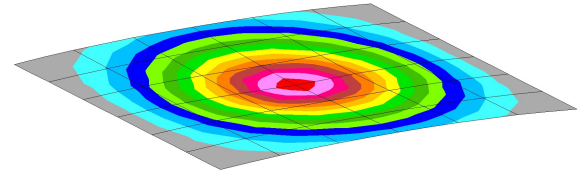

Figure 12. Deformation for a concentrated load (thickness=12 mm)

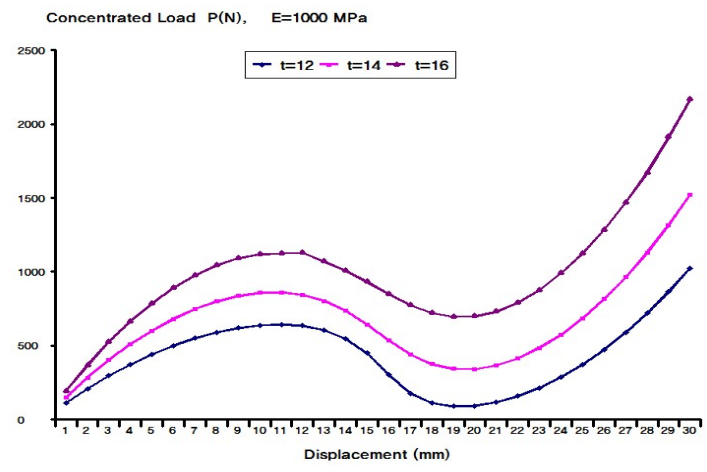

Figure 13. Load displacement curves of a cylindrical shell with two edge hinges (elastic modulus $=1000 \mathrm{MPa}$, thickness=12, 14, $16 \mathrm{~mm}$ )

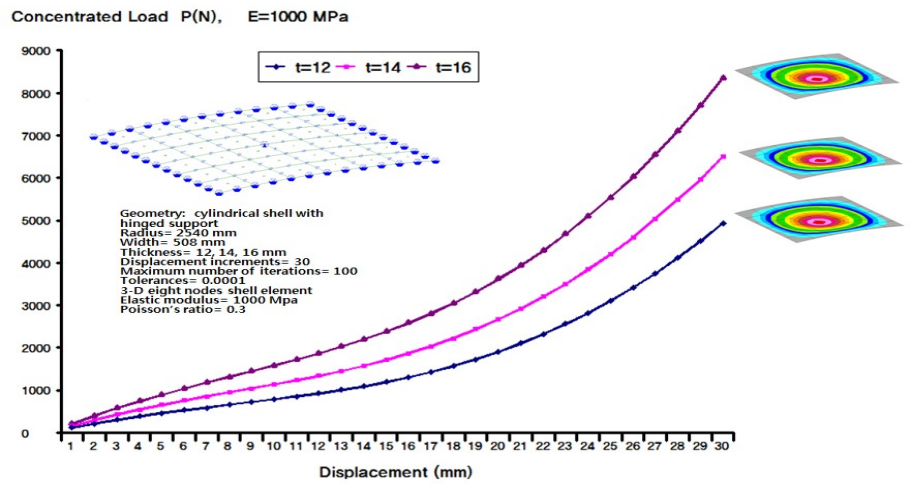

Figure 14. Load displacement curves of a cylindrical shell with four edge hinges (elastic modulus $=1000 \mathrm{MPa}$, thickness=12, 14, $16 \mathrm{~mm}$ )

\section{B. A cylindrical shell with fixed support -}

This objective is to investigate the load displacement curve of a cylindrical shell with fixed support. The radius of a spherical shell is $2540 \mathrm{~mm}$. The width is $508 \mathrm{~mm}$. The elastic modulus is $1000 \mathrm{MPa}$. The fixed boundary conditions are applied on nodes of two edges and four edges. Figure 15 shows analytical model and geometry of meshes for analysis. Figure 16 is a deformation of a shell with thickness $12 \mathrm{~mm}$ in displacement range 0-30 mm. In Figure 17 the results of a cylindrical roof with fixed supports are compared with load displacement curves for the thickness 12 , 14 and $16 \mathrm{~mm}$. In Figure 18 the results of a shell with four edge fixed supports are compared with load displacement curves for the thickness 12,14 and $16 \mathrm{~mm}$. The snap through behavior is not observed in Figure 17 and 18.

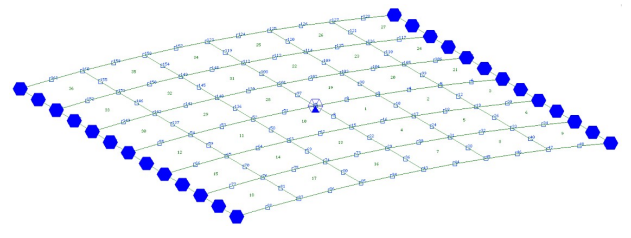

Figure 15. Analytical modeling (thickness=12, 14, 16mm)

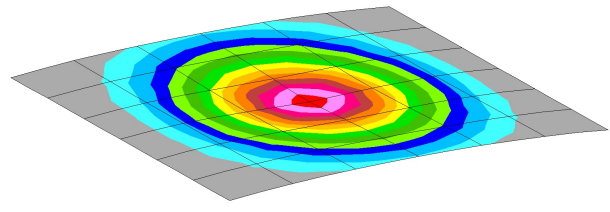

Figure 16. Deformation for a concentrated load (thickness=12 $\mathrm{mm}$ ) 


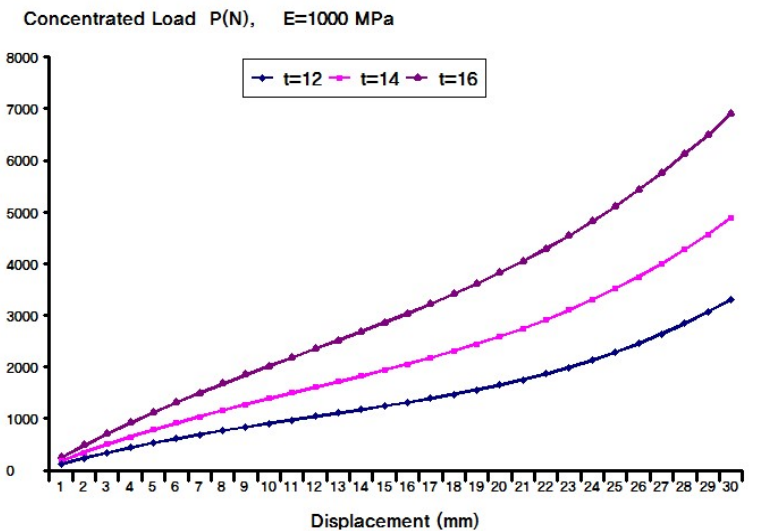

Figure 17. Load displacement curves of a cylindrical shell with 2 edge fixed support (elastic modulus $=1000 \mathrm{MPa}$, thickness=12, 14, $16 \mathrm{~mm}$

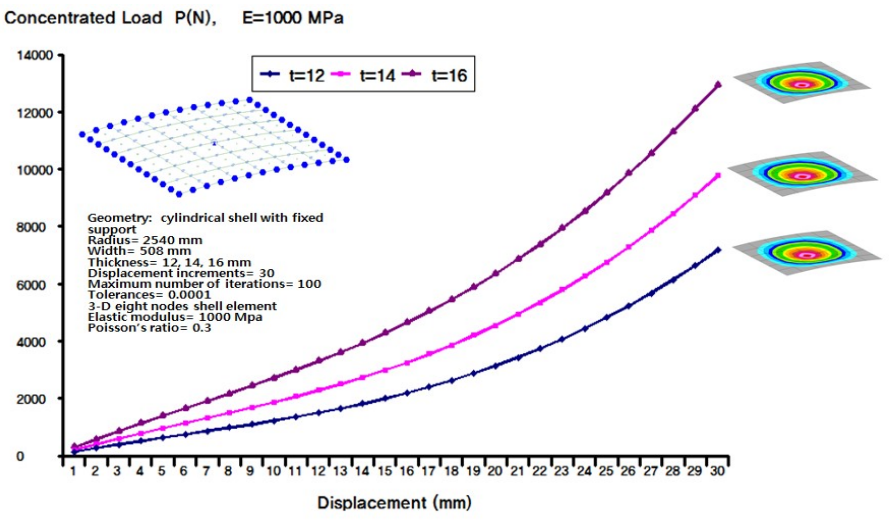

Figure 18. Load displacement curves of a cylindrical shell with 4 edge fixed support (elastic modulus=1000 MPa, thickness=12, 14, 16 mm)

\section{GEOMETRICAL NONLINEAR BEHAVIOR OF A QUADRATIC COMPOSITE SHELL}

The quadratic composite shell with 7 layers is subjected to a central point load. The objective is to obtain the load deflection curve for the hinged support and fixed support. The 3-D composite shell element is used for the modeling of analysis. The results of geometrical nonlinear analysis are shown in Figure 19. In the principal material direction the material properties are assumed elastic modulus $\mathrm{Ex}=\mathrm{Ey}=\mathrm{Ez}=300 \mathrm{MPa}$ and shear modulus $\mathrm{Gxy}=\mathrm{Gyz}=\mathrm{Gxz}=115$ MPa. The total thickness is $35 \mathrm{~mm}$. The load deflection curve of the center point is compared with according to support conditions in Figure 19. The similar load displacement curve is observed. 


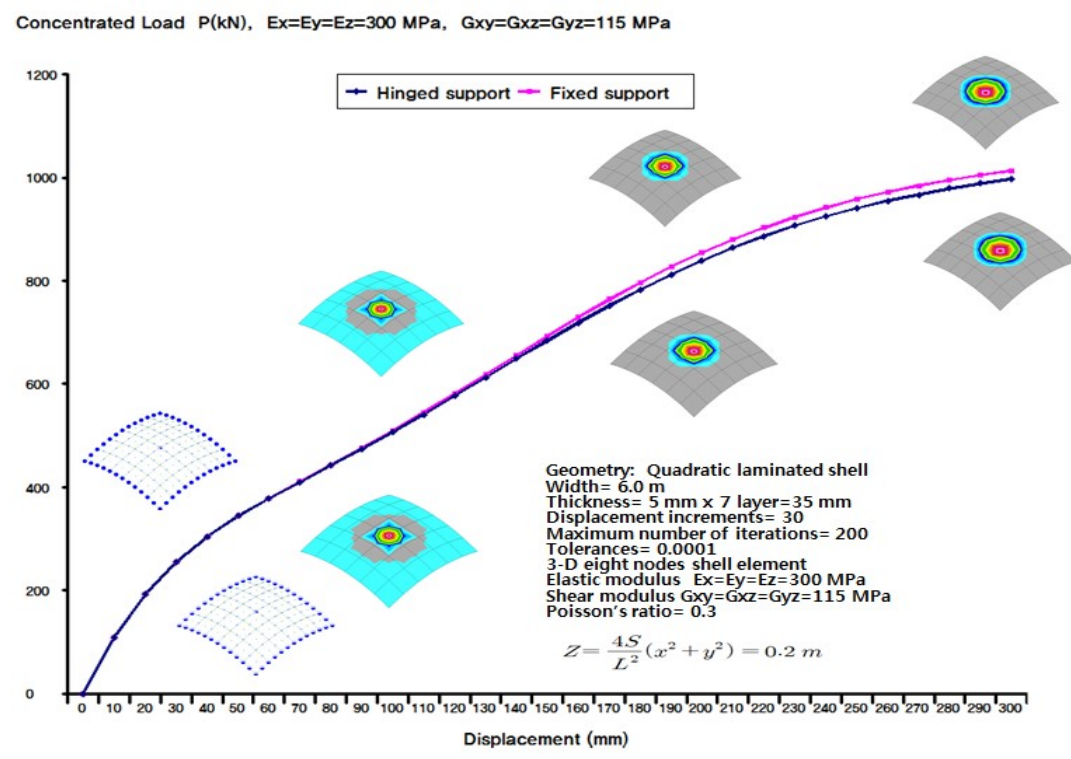

Figure 19. Load displacement curves of a quadratic composite shell (elastic modulus $=300 \mathrm{MPa}$, thickness $=35 \mathrm{~mm}$ )

\section{CONCLUSION}

The research is to investigate the mechanical characteristics of geometrical nonlinear behavior for a spherical shell, a cylindrical shell and a quadratic shell applied to a concentrated load. The geometry of shells is composed of shallow shapes because the load displacement curve is possible to plot snap back and through phenomenon.

(a) A shallow spherical shell with hinged supports and a concentrated load observes a snap through behavior in the load deflection curve, the shell with fixed supports is not found out the snap through curve.

(b) A cylindrical shell with two edge hinged supports and a concentrated load only can find the snap through phenomenon, the other hinged and fixed support is not observed for the snap through curve.

(c) A quadratic composite shell with a concentrated load at the center is not occurs the snap through phenomenon on load deflection curve.

(d) The shallow shells with fixed support conditions at edges are increasing greatly the structural capacity that can resist an applied load.

\section{ACKNOWLEDGEMENTS}

(a) This research was supported by a grant (17AUDP-B100343-03) from Architecture \& Urban Development Research Program funded by Ministry of Land, Infrastructure and Transport of Korean government.

(b) This research was supported by a grant (17CTAP-C115046-02) from Technology Advancement Research Program (TARP) funded by Ministry of Land, Infrastructure and Transport of Korean government

\section{REFERENCE}

[1] K.S Surana, "Geometrically Nonlinear Formulation for the Curved Shell Elements," International Journal for Numerical met5hod in Enginering, 19, 581-615, 1983

[2] R. Sziliard, "An Energy Balancing Strategy for Solution of Combined Geometric Material Nonlinearity Problems," Computer \& Structures, 23, 147-162, 1986

[3] Y.H. Kim and S.W. Lee, A Solid element Formulation for Large deflection Analysis of Composite Shell Structures, Computer \& Structures, 30, 269-274, 1988

[4] K.G. Park, M.H. Lee, M.J. Park, "Nonlinear Behaviors of Cable Spoke Wheel Systems," Journal of Korean Association for Spatial Structures, Vol.17(No.1), pp.31-40, 2017

[5] K.G. Park, D.W. Lee, D.I. Choe, "Mechanical Characteristics of Retractable Radial Cable Roof Systems," Journal of Korean Association for Spatial Structures, Vol.17(No.2), pp.21-32, 2017

[6] K.G. Park, D.W. Lee, M.J. Park, "Mechanical Characteristics of Circular Cable Roof Systems," International Journal of Innovations in Engineering and Technology, Vol.8(3), pp.296-302, 2017 